\title{
Desenvolvimento de ferramenta digital para otimizar o uso de dados no planejamento e cuidado em saúde
}

Gustavo Guerchon ${ }^{1}$ | Marcelo Witeki de Almeida' | Marcelo Nadur Caiafa' | Rubens Kon ${ }^{2}$ | Katia Lima dos Santos ${ }^{3}$ 1: Residente de Medicina Preventiva e Social da FMUSP; 2: Médico Sanitarista da FMUSP ; 3: Gerente da UBS Jardim Lourdes

\section{INTRODUÇÃO}

A longitudinalidade do cuidado em saúde demanda um acompanhamento sistemático do paciente; porém a realização de um monitoramento adequado para planejá-lo é um desafio fundamental nos serviços de saúde. Além de auxiliar no cuidado, o monitoramento fornece informações significativas sobre as características da população assistida, o que permite mapear as ações a serem desenvolvidas pelo serviço. O presente estudo visa ilustrar as dificuldades encontradas no monitoramento dos pacientes em uma unidade básica de saúde (UBS), e apresentar a solução concebida no âmbito de um estágio de residência médica.

\section{METODOLOGIA}

Foi realizado um diagnóstico situacional em uma UBS da cidade de São Paulo através de entrevistas semiestruturadas com a gerência e com as equipes da Saúde da Família. A solução desenvolvida utiliza o software Microsoft Excel ${ }^{\circledR}$ e a linguagem de programação VBA para automatizar a extração de dados dos relatórios gerados pelo sistema de informação da Secretaria Municipal da Saúde de São Paulo.

\section{RESULTADOS/DISCUSSÃO}

Durante as entrevistas, foi identificado que o monitoramento da frequência dos pacientes com condições que necessitam de atendimentos periódicos, ou gera sobrecarga de trabalho às equipes assistenciais, ou simplesmente não é realizado, prejudicando a longitudinalidade e o planejamento das ações. Além disso, os dados disponíveis pelo sistema da prefeitura não são empregados com esse objetivo, apesar de sua potencialidade para tanto. Para auxiliar nesse processo, foi desenvolvido o motoSIGA, uma planilha automatizada de monitoramento de pacientes que inclui dados como tempo transcorrido desde a última consulta, condição crônica do indivíduo assistido, estratificação de risco, e alerta de cores para reconvocação. Por utilizar o relatório gerado por um sistema de gestão amplamente usado no município de São Paulo, o motoSIGA é implementável em outros serviços que também o utilizem. O motoSIGA evidencia que dados produzidos por equipes assistenciais com variadas finalidades, como dados referentes à produtividade, podem gerar valor para ela mesma, motivando potencial melhoria na qualidade da coleta de dados, além de aperfeiçoar o cuidado ao paciente.

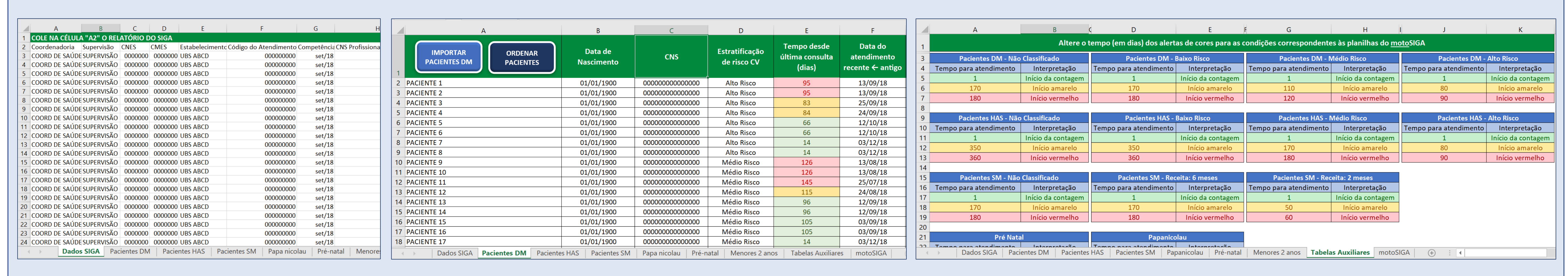

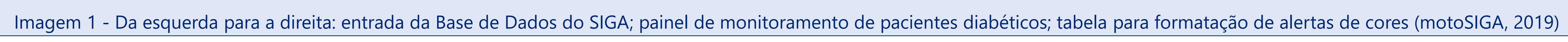

